\title{
Public Responses to Intimate Partner Violence Against Women: The Influence of Perceived Severity and Personal Responsibility
}

\author{
Enrique Gracia, Fernando García, and Marisol Lila \\ Universitat de València (Spain)
}

This paper explored public willingness to act when exposed to cases of intimate partner violence against women, by analyzing the influence of perceived severity and personal responsibility on two types of responses: mediating and reporting to the police. Results $(\mathrm{N}=419)$ yielded main effects of personal responsibility for both types of responses. No main effects of perceived severity were found. A significant interaction between perceived severity and personal responsibility was found only for reporting responses. Results are discussed in light of the helping behavior research tradition. Implications for public education and advocacy programs are also considered.

Keywords: intimate partner violence, public responses, perceived severity, personal responsibility, violence against women, tolerance.

\begin{abstract}
Este trabajo analizó la influencia que la gravedad percibida y el sentimiento personal de responsabilidad tienen en dos tipos de respuestas públicas ante escenarios hipotéticos de violencia doméstica contra la mujer: la mediación y la denuncia. Los resultados $(\mathrm{N}=419)$ mostraron efectos principales del sentimiento de responsabilidad personal para ambos tipos de respuesta. No se observaron efectos principales de la gravedad percibida. Se observó una interacción significativa entre la gravedad percibida y la responsabilidad personal únicamente para las respuestas de denuncia. Los resultados se discuten en términos de la tradición investigadora de la conducta de ayuda. Se consideran las implicaciones de los resultados para la educación pública y la intervención social.

Palabras clave: gravedad percibida, responsabilidad personal, respuestas públicas, violencia contra la mujer, violencia del compañero íntimo, tolerancia.
\end{abstract}

Support for this research was provided by a grant from the Spanish Ministry of Work and Social Affairs (MUJER2007-PI-090).

Correspondence concerning this article should be addressed Enrique Gracia, Departamento de Psicología Social, Facultad de Psicología, Universitat de València, Avda. Blasco Ibáñez 21, 46010 Valencia (Spain). E-mail: enrique.gracia@uv.es 
Despite the high prevalence of intimate partner violence against women (IPVAW) in western societies, with life time prevalence ranging between $25 \%$ and $30 \%$, and annually between 2\% and 12\% (e.g., American Medical Association, 1994; Bachman \& Saltzman, 1995; Browne, 1993; Council of Europe, 2002; Kury, Obergfell-Fuchs \& Woessner, 2003; Nadine, Wathen, Harriet, \& MacMillan, 2003; Straus \& Gelles, 1986; Walker, 1999; World Health Organization, 2002), most cases are seldom reported to the authorities (American Psychological Association Presidential Task Force on Violence and the Family, 1996; Bachman \& Saltzman, 1995; Gracia, 2004; Kaufman-Kantor \& Straus, 1990). Indications are, however, that many of those cases not reported to the authorities are known within the social circle of the victim (e.g., relatives, neighbors, friends, co-workers, acquaintances). For example, in the USA, the Lieberman Survey found that almost $30 \%$ of the respondents reported that they knew a woman who was currently a victim of physical abuse (Klein, Campbell, Soler, \& Ghez, 1997). Also, in a survey with a representative sample of 15 countries of the European Union (European Commission, 1999; Gracia \& Herrero, 2006a), 36\% of male and $45 \%$ of female respondents knew a victim of IPVAW in their social circle of work, studies, family, neighborhood or friends.

Those surrounding the victims of IPVAW tend to respond in different ways when an incident of IPVAW is known (Biden, 1993; Jenkins, 1996). Of course, silence ("doing nothing") is a potential response to known incidents of IPVAW (Biden, 1993; Gracia, 2004; Jenkins, 1996; Klein et al., 1997). For example, in a Spanish national survey (Centro de Investigaciones Sociológicas, 2004), the most common response among those respondents who knew a case of partner violence against women $(22,9 \%)$ was not to report it $(71,5 \%)$ (see Gracia \& Herrero, 2006b for secondary analyses of this survey). As Jenkins (1996) noted, silence remains a prevalent community response to IPVAW, and those who know about the violence but choose to be silent and passive contribute to "perpetuate a regime of silence, denial, and neglect -a regime in which survivors assume they will not be believed and outsiders continue to disbelieve" (Biden, 1993, p. 1060). Furthermore, responses of silence, passivity and inhibition sometimes implicitly condone or even support violence against women (Bennet \& Williams, 1999; Biden, 1993; Jenkins, 1996; Klein et al., 1997). In many instances, however, the social environment surrounding the victim of IPVAW is willing to act, responding in different ways when an incident of IPVAW is known. These responses to IPVAW can be classified broadly into two types (Gracia \& Herrero, 2006a; Mahlstedt \& Keeny, 1993; West \& Wandrei, 2002): mediating responses (e.g., offering help, support and understanding, advising, helping with decision making, talking to the couple, or reproaching the offender), and reporting responses (i.e., responses that set the law enforcement in motion by reporting the incident to the authorities). Research focusing on public responses to incidents of IPVAW, however, has been sparse compared to the scholarly attention paid to other issues such as prevalence, consequences or intervention. This paper aims to contribute to fill this gap by exploring the influence of perceived severity and sense of personal responsibility on two types of public responses to incidents of IPVAW: mediating responses and reporting to the police.

\section{The present study}

In this study we draw from the helping behavior research tradition (García, Weaver, Moskowitz, \& Darley, 2002; Staub, 2003; see Batson, 1998; for a review) to explore the influence of perceived severity and sense of personal responsibility on public responses to cases of IPVAW. According to Latané and Darley's (1970) model of bystander intervention, perceived severity and personal responsibility are preconditions in a decision tree leading to the decision to intervene. In this model, if they are to intervene, bystanders must notice the event (a situation of IPVAW), interpret it as an emergency (is it serious enough?), feel personally responsible (is it my business?), and posses the necessary skills and resources to act (e.g., can I mediate, or pick up the phone to call the police?).

According to this model, if some incidents of IPVAW are perceived as acceptable or not serious enough (e.g., threats, non severe physical aggression) is less likely that bystanders will be willing to intervene. For example, research showed that a higher level of tolerance (i.e., some levels of violence are normal or acceptable) is associated with negative attitudes toward reporting (Gracia \& Herrero, 2006b). Research also showed that when bystanders feel that a particular situation is "none of my business" (Shotland \& Straw, 1976, p. 993) they tend not to intervene. Darley and Latané, (1970) also suggested that, in certain circumstances (e.g., married couples), norms for helping may conflict with norms of not helping. Bystanders would have to face the potential conflicts between norms of social responsibility (e.g. report a women in danger), and social norms concerning "private matters" (e.g. mind your own business). These social norms "guide both the interpretation of events and also decisions about the legitimacy of intervention" (Levine, 1999, p. 1151). In addition, from a cost-reward perspective (Piliavin, Dovidio, Gaertner, \& Clark, 1981) the lower the sense of responsibility to help, the lower the psychological costs for not helping, and the lower the probability of help being offered. Also, from this perspective, the decision to intervene (and how to intervene) will depend on the result of the evaluation of the probable costs and rewards of different courses of action (e.g., doing nothing, mediating between offender and victims, or reporting to the police a known incident of IPVAW).

Drawing from these ideas, in this paper we will analyze the influence of perceived severity of incidents of IPVAW and the sense of personal responsibility on public responses to cases of IPVAW. Two types of public responses to incidents of IPVAW will be considered: (1) Mediating 
responses (advising, helping, talking, etc.), and (2) Reporting responses (reporting incidents of IPVW to the police). The following hypotheses will be tested:

1. The higher the perceived severity of incidents of IPAW, the higher the number of both mediating and reporting responses.

2. The higher the sense of personal responsibility, the higher the number of both mediating and reporting responses.

Finally, we used 5 socio-demographic controls (gender, age, marital status, education, and income), as sociodemographic variables have been related to helping behavior, and attitudes toward domestic violence (see Batson, 1998; Eagly \& Crowley, 1986; Latané \& Nida, 1981; West \& Wandrei, 2002; Worden \& Carlson, 2005, for reviews).

\section{Method}

\section{Participants}

Adults (aged 18-65 years) were recruited from Spanish Valencia City neighborhoods (near 800000 inhabitants and 87 neighborhoods) through door-to-door-canvassing. To enhance the representativeness of selected neighborhoods, the neighborhoods in the city were stratified by quartile of average household wealth, and three neighborhoods in each stratum were randomly selected. We use the Department of Statistics of the city listing housing-units as a sampling frame for probability sampling in the twelve neighborhoods. A quota sampling strategy of gender and age was used to have similar number of men and women in different age groups. Trained interviewers carried letters from the University Department responsible for the research, and from the Department of Social and Community Services of the city describing the collaboration with the university and the possible use of the study's data as they may orientate their policies. Anonymity was assured to participants.

It was estimated that a sample size of 412 would be required to detect a medium effect size $(f=.25)$ in an $F$-test with one-degree-of-freedom (main effect or interaction) with 99.9\% power using G*Power 3 (Faul, Erdfelder, Lang, \& Buchner, 2007; García, Pascual, Frías, Van Krunckelsven, \& Murgui, 2008). Of all participants contacted, a total of 419 adults completed the instruments, $15 \%$ refused to participate (most of them men, which explains the lower number of men in our sample). Socio-demographic characteristics of the sample are presented in Table 1.

\section{Measures}

To measure variables of interest, in this study we used an instrument originally designed to assess police responses to hypothetical scenarios describing incidents of IPVAW (Gracia, García, \& Lila, 2008). Selection of these
Table 1

Socio-demographic characteristics of the sample $(N=419)$

\begin{tabular}{lrr}
\hline Characteristic & $N$ \\
\hline Gender & & \\
& Male & 174 \\
& Female & 245
\end{tabular}

Marital Status

$$
\begin{array}{rr}
\text { Single } & 204 \\
\text { Married/living with a partner } & 215
\end{array}
$$

Educational Level $^{\mathrm{a}}$

$\begin{aligned} \text { Low } & 115 \\ \text { Medium } & 142 \\ \text { High } & 160\end{aligned}$

Income

$$
<10,000 € \quad 102
$$

$10,000-20,000 € \quad 102$

$20,001-30,000 € \quad 67$

$>30,000 € \quad 63$

Average Age $(S D)$

$35.8(15.38)$

${ }^{\mathrm{a}}$ Years of full time education: Low $=$ up to 14 ; Medium $=15-17$; High $=18+$

hypothetical scenarios was based on items used in the Spanish National Incidence Survey (Instituto de la Mujer, 2003), and on the advice and experience of communitybased experts dealing with the problem of IPVAW (social services personnel, and senior police officers) who were assembled to assist in the development of the instrument (see Schuller \& Stewart, 2000; Sorenson, \& Taylor, 2005, for a similar approach). The Spanish National Incidence Survey, in addition to questions regarding whether a woman considers herself to be a victim of partner violence, uses 13 items to "technically" define abused women. These items were used as the starting point to define the hypothetical scenarios. With the help of the community-based experts, 8 scenarios were finally developed to reflect situations of IPVAW that social services and police officers usually come across in their work. The scenarios were also developed with the intention that they differ in severity of the violence. These scenarios included psychological violence (e.g., "A woman is often verbally abused and humiliated by her partner"), threats (e.g., "A couple is having a quarrel; he insults her and threatens to beat her up"), and different degrees of physical violence (e.g., "While having a quarrel, he hits her partner and afterwards he asks her for forgiveness"; "A woman is frequently beaten up by her partner causing sometimes small injuries and bruises, but still she does not want to report the maltreatment").

Perceived severity. To measure the perceived severity of incidents of IPVAW, participants had to rate on a 10 point scale the severity of the 8 hypothetical scenarios of IPVAW. Cronbach's alpha value for this scale was .88. A 
general index was obtained averaging the 8 raw responses so that higher scores represent higher perceived severity of incidents of IPVAW (highest score for the scale $=10$ ).

Personal responsibility. To measure the sense of personal responsibility to act in cases of IPVAW participants had to rate on a 10-point scale their sense of personal responsibility to act in the same 8 hypothetical scenarios of IPVAW. Cronbach's alpha value for this scale was .93. A general index was obtained averaging the 8 raw responses so that higher scores represent a greater sense of personal responsibility (highest score for the scale $=10$ ).

Responses to cases of IPVAW. Public responses to cases of IPVAW were evaluated using a scale in which participants had to decide whether they would (Yes) or would not (No) use different responses to 8 hypothetical scenarios of IPVAW (same as those used in the above scales). Six different responses to the hypothetical scenarios of IPVAW represented two types of responses: (1) Mediating: was evaluated with 5 items representing mediating responses (e.g., "I would talk to relatives"; "I would offer advice to the couple", "I would reprimand the man"). Cronbach's alpha $=.79$. (2) Reporting, was evaluated with an item representing a public response that set the law enforcement in motion by reporting the incident to the authorities ("I would report it to the police"). Cronbach's alpha $=.73$. Cronbach's alpha for the overall scale was .81 . For each respondent a score for each type of responses was computed by summing all "yes" response (mediating: "yes" $=.25$, "no" $=0$; reporting: "yes" = 1.25 , "no" =0). So that higher scores represent a greater sense of mediating and reporting, respectively (highest score for each scale $=10$ ).

\section{Results}

\section{Preliminary analyses}

First, we tested for differences in the variables of interest (perceived severity of incidents of IPVAW, sense of personal

Table 2

Means and (standard deviations) of severity, responsibility and two type of responses. MANOVAs and ANOVAs between groups of demographics variables

\begin{tabular}{|c|c|c|c|c|}
\hline & \multirow[b]{2}{*}{ Severity } & \multirow[b]{2}{*}{ Responsibility } & \multicolumn{2}{|c|}{ Type of response } \\
\hline & & & Mediating & Reporting \\
\hline Gender & \multicolumn{3}{|c|}{$\Lambda=.943 ; F(4,387)=5.827 ; p<.001$} & \\
\hline Male $\{159\}$ & $8.75(1.06)$ & $6.88(1.92)$ & $6.81(2.02)$ & $2.82(1.73)$ \\
\hline Female $\{233\}$ & $9.12(.95)$ & $7.54(1.79)$ & $7.28(1.85)$ & $2.72(1.75)$ \\
\hline$F(1,390)$ & $13.63 * *$ & $12.27 * *$ & $5.78^{*}$ & .28 \\
\hline Age & \multicolumn{3}{|c|}{$\Lambda=.927 ; F(8,772)=3.719 ; p<.001$} & \\
\hline$<25$ years $\{141\}$ & $8.94(1.01)$ & $7.17(1.88)$ & $6.99(1.66)$ & $2.40(1.41)^{\mathrm{b}}$ \\
\hline $25-45$ years $\{136\}$ & $9.20(.89) \mathrm{a}$ & $7.63(1.72)^{\mathrm{a}}$ & $7.26(1.79)$ & $2.85(1.71)$ \\
\hline$>45$ years $\{115\}$ & $8.74(1.09) \mathrm{b}$ & $6.98(1.99)^{\mathrm{b}}$ & $7.00(2.36)$ & $3.10(2.04)^{\mathrm{a}}$ \\
\hline$F(2,389)$ & $6.90 * *$ & $4.14^{*}$ & .83 & $5.65 * *$ \\
\hline Marital status & \multicolumn{3}{|c|}{$\Lambda=.980 ; F(4,387)=1.972 ; p=.098$} & \\
\hline Married $\{198\}$ & $9.01(.99)$ & $7.30(1.89)$ & $7.30(1.95)$ & $2.95(1.82)$ \\
\hline Single $\{194\}$ & $8.93(1.04)$ & $7.24(1.86)$ & $6.87(1.90)$ & $2.57(1.63)$ \\
\hline Education & \multicolumn{3}{|c|}{$\Lambda=.918 ; F(8,768)=4.219 ; p<.001$} & \\
\hline Low $\{105\}$ & $8.69(1.14)^{\mathrm{b}}$ & $7.05(1.87)$ & $6.60(2.34)^{b}$ & $2.77(1.84)$ \\
\hline Medium $\{125\}$ & $9.09(.92)^{\mathrm{a}}$ & $7.14(1.93)$ & $6.91(1.84)^{\mathrm{b}}$ & $2.89(1.91)$ \\
\hline High $\{160\}$ & $9.05(.96)^{\mathrm{a}}$ & $7.50(1.81)$ & $7.53(1.59)^{\mathrm{a}}$ & $2.67(1.52)$ \\
\hline$F(2,387)$ & $5.36^{* *}$ & 2.30 & $8.24 * *$ & .54 \\
\hline Income & \multicolumn{3}{|c|}{$\Lambda=.948 ; F(12,812.537)=1.367 ; p=.176$} & \\
\hline$<10,000 €\{97\}$ & $9.04(1.01)$ & $7.27(1.91)$ & $6.95(1.93)$ & $2.64(1.77)$ \\
\hline $10,000-20,000 €\{94\}$ & $8.79(1.18)$ & $7.09(1.90)$ & $6.82(2.04)$ & $2.60(1.35)$ \\
\hline $20,001-30,000 €\{60\}$ & $9.15(.85)$ & $7.31(1.81)$ & $7.23(2.06)$ & $2.89(1.99)$ \\
\hline$>30,000 €\{63\}$ & $9.18(.85)$ & $7.40(1.80)$ & $7.60(2.00)$ & $3.32(2.05)$ \\
\hline
\end{tabular}

Note. $\{n\}$ of group with listwise deletion. Means with different superscript differ significantly at $p<.05$ Bonferroni multiple-comparison procedure.

$* p<.05, * * p<.01$ 
responsibility, and type of responses to incidents of IPVAW as a function of the socio-demographic variables (gender, age, marital status, education, and income). Five one-way multivariate analyses of variance (MANOVAs) revealed significant multivariate effects of gender, age, and education (see Table 2). The univariate effects with multiple comparisons using Bonferroni adjustment indicated that women perceived the same hypothetical scenarios of IPVAW as more severe, felt more personal responsible to act, and were more inclined to use mediating responses than men. Those in the 25-45 age group also perceived the same scenarios as more severe and felt more personal responsible than those in the $>45$ years old group, however the youngest were those who felt less inclined to report the incidents to the police than the $>45$ years. In relation to education, the less educated perceived that the hypothetical scenarios of IPVAW were less severe, whereas the better educated were more willing to mediate.

\section{Perceived severity, personal responsibility and public responses to cases of IPVAW}

A repeated-measures ANOVA was computed to examine the effects of perceived severity (low vs. high) and personal responsibility (low vs. high) on public responses to incidents of IPVAW (mediating and reporting). For this analysis, groups of perceived severity (low vs. high) and personal responsibility (low vs. high) were formed according to the median score of each scale. The results (see Table 3 ) yielded main effects of type of responses, $F(1,388)=1779.30, p<.001$, indicating that, in general, participants preferred mediating responses to IPVAW scenarios, $M=7.09, S D=1.93$, than reporting to the police, $M=2.76, S D=1.74$ (see Table 5). Results also yielded main effects of sense of personal responsibility, $F(1,388)=27.90, p<.001$, as well as the interactions between perceived severity and personal responsibility, $F(1$, $388)=6.38, p<.05$, and between personal responsibility and type of public response, $F(1,388)=15.19, p<.001$. No significant interactions were found between sociodemographic controls and independent variables (perceived severity and personal responsibility). We next explored the effects of sense of personal responsibility and the interaction between personal responsibility and perceived severity for each type of responses to incidents of IPVAW (see Table 4).

Effects of perceived severity and personal responsibility on mediating responses to IPVAW. For mediating responses, only main effects of personal responsibility yielded significant differences, $F(1,388)=40.83, p<.001$ (Table $4)$. This indicates that those participants with greater sense of personal responsibility are more willing to mediate,

Table 3

$2 \times 2 \times 2$ Factorial design. Effects of perceived severity and personal responsibility on public responses to IPVAW

\begin{tabular}{|c|c|c|c|c|}
\hline Source & & $\mathrm{F}_{(1,388)}$ & $p$-value & partial eta-squared \\
\hline \multicolumn{5}{|c|}{ Within-subjects } \\
\hline & Type of response & 1779.30 & $<.001$ & .821 \\
\hline & Severity $\times$ Type of response & 1.96 & .163 & .005 \\
\hline & Responsibility $\times$ Type of response & 15.19 & $<.001$ & .038 \\
\hline & Severity $\times$ Responsibility $\times$ Type of response & .51 & .478 & .001 \\
\hline \multicolumn{5}{|c|}{ Between-subjects } \\
\hline & Severity & 2.10 & .148 & .005 \\
\hline & Responsibility & 27.90 & $<.001$ & .067 \\
\hline & Severity $\times$ Responsibility & 6.38 & .012 & .016 \\
\hline
\end{tabular}

Table 4

$2 \times 2$ Factorial design for each type of public response: mediating and reporting

\begin{tabular}{|c|c|c|c|c|}
\hline Source & & $\mathrm{F}_{(1,388)}$ & $p$-value & partial eta-squared \\
\hline \multicolumn{5}{|l|}{ Mediating } \\
\hline & Severity & 3.74 & .054 & .010 \\
\hline & Responsibility & 40.83 & $<.001$ & .095 \\
\hline & Severity $\times$ Responsibility & 2.74 & .099 & .007 \\
\hline & & $F_{(1,389)}$ & $p$-value & partial eta-squared \\
\hline \multicolumn{5}{|l|}{ Reporting } \\
\hline & Severity & .15 & .699 & $<.001$ \\
\hline & Responsibility & 5.39 & .021 & .014 \\
\hline & Severity $\times$ Responsibility & 6.84 & .009 & .017 \\
\hline
\end{tabular}


Table 5

Means and (standard deviations) for Type of Response (mediating and reporting) by Perceived Severity (low vs. high), and Type of Response by Personal Responsibility (low vs. high)

\begin{tabular}{|c|c|c|c|c|c|}
\hline \multirow{2}{*}{ Type of response } & & & \multicolumn{2}{|c|}{ Responsibility } & \multirow{2}{*}{ Overall } \\
\hline & & & low & high & \\
\hline \multirow[t]{4}{*}{ Mediating } & & & & & $7.09(1.93)$ \\
\hline & Severity & low & $6.40(1.58)$ & $7.29(1.87)$ & \\
\hline & & high & $6.45(2.01)$ & $7.97(1.85)$ & \\
\hline & & Overall & $6.42(1.76)$ & $7.72(1.88)$ & \\
\hline \multirow[t]{4}{*}{ Reporting } & & & & & $2.76(1.74)$ \\
\hline & Severity & low & $2.69(1.72)$ & $2.64(1.36)$ & \\
\hline & & high & $2.29(1.49)$ & $3.17(2.00)$ & \\
\hline & & Overall & $2.53(1.64)$ & $2.97(1.74)$ & \\
\hline
\end{tabular}

$M=7.72, S D=1.88$, than those participants with lower sense of responsibility, $M=6.42, S D=1.76$ (see Table 5).

Effects of perceived severity and personal responsibility on reporting responses to IPVAW. For reporting responses, results yielded main effects of personal responsibility, $F(1$, $389)=5.39, p<.05$, as well as the interaction between perceived severity and personal responsibility, $F(1,389)=$ $6.84, p<.01$ (Table 4). To examine the interaction between perceived severity and personal responsibility, all pairwise comparisons of means using Bonferroni adjustment were conducted. Significant differences were found between low and high responsibility groups only in the group of high perceived severity, $F(1,389)=12.405, p<.01$ (see Figure $1)$. This indicates that those who feel more personal responsible and perceive the same incidents of IPVAW as more severe (high perceived severity group) are more willing to report them to the police, $M=3.17, S D=2.00$, as compared to those that perceive the same severity but feel less responsible, $M=2.29, S D=1.49$ (see Table 5 and Figure 1 ).

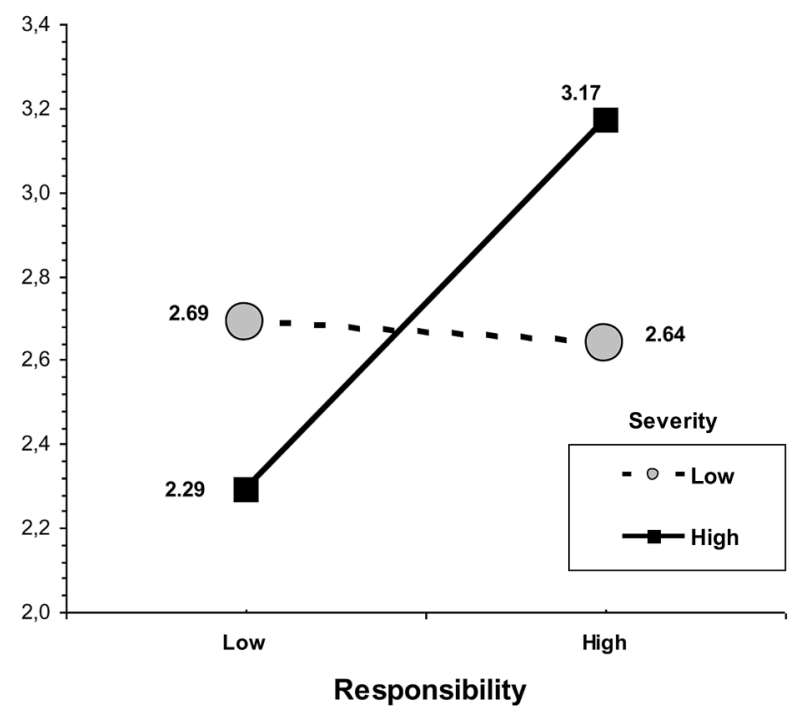

Figure 1. Means of reporting responses as a function of perceived severity by personal responsibility levels.

\section{Discussion}

In this paper we aimed to explore the influence of perceived severity and personal responsibility on two types of responses to cases of IPVAW: mediating responses and reporting to the police. Hypotheses were partially supported, and sense of personal responsibility emerged from our results as a central variable influencing public responses to cases of IPVAW. The study yielded also some interesting results concerning the interactive effects of perceived severity, and sense of personal responsibility for reporting responses.

First, participants exposed to hypothetical scenarios of IPVAW, preferred mediating responses $(M=7.09$, in a scale from 1 to 10$)$ than reporting responses $(M=2.76$, in a scale from 1 to 10). This indicates that, in general, reporting to the police was considered as an appropriate response only exceptionally, whereas mediating responses were considered typically as more appropriate. This preference for mediating responses could indicate that the social circle surrounding the women victims of IPVAW assume or believe that, in most instances, they will prefer the help and advice of friends and family members rather than to involve the law enforcement system (Rhodes \& McKenzie, 1998; Sipsma, Carrobles, Cerrato, \& Everaerd, 2000; West \& Wandrei, 2002). A response such as reporting to the police is probably viewed as a last resource only to be used for extreme cases of IPVAW (Gracia \& Herrero, 2006b; Loseke, 1989; Loseke \& Gelles, 1993; Muehlenhard \& Kimes, 1999). Perhaps this kind of response is considered appropriate only for incidents that reach an "intolerable" level of violence (i.e., extreme, severe or repeated violence). Other instances of IPVAW (perhaps most instances) that are not considered as such, and consequently do not reach the "intolerable" level (i.e. totally unacceptable and always punishable by law), would deserve a more "tolerant" response (i.e., mediative responses). As Worden and Carlson (2005) noted, it is unlikely to use legal protections, or to recommend its use to others, if one believes that some levels of violence are normal or justifiable, or that women are responsible for managing their partners' 
behavior. Reporting responses may be considered appropriate only for incidents where the victim is perceived not to be involved, either in mutual violence or fighting back (Johnson $\&$ Ferraro, 2000). Women were also more willing to mediate than men, perceived the same hypothetical scenarios of IPVAW as more severe, and felt more personal responsible to act than men, which suggest greater empathy for the victims of IPVAW (West \& Wandrei, 2002). This results support previous research in the European Union showing that women perceived more severity and accepted IPVAW less than men (Gracia \& Herrero, 2006a). Also, the older perceived the same scenarios as less severe and felt less personally responsible than those in the middle age group, which seems to support Worden and Carlson's (2005) findings that older respondents are more likely to accept violence as normal and justifiable. However, this may also indicate a shift in the culture over time. Perhaps the older participants lived in a time when people did feel less responsible for these issues more than they do in the present, and our data does not necessarily suggest that older individuals accept violence as normal. No significant interactions were found, however, between these socio-demographic variables and predictor variables (perceived severity and personal responsibility).

When we explored the influence of perceived severity and sense of personal responsibility on each type of public responses to incidents of IPVAW, we found that those respondents who felt more personally responsible were more willing to mediate in the same scenarios of IPVAW than those participants in the group of low personal responsibility. According to our results, individual differences in perceived severity appear not to play a role in distinguishing those more willing to mediate when exposed to incidents of IPVAW, from those less willing to mediate in the same scenarios. What seems to matter for this type of response is the sense of personal responsibility, that is, the sense of obligation to a situation of IPVAW that, in terms of behavior management, is an internal reason to act (Watson \& Tharp, 1993). These results suggest that for some respondents the norm for helping is more salient than the norm for not helping (Darley \& Latané, 1970). Accordingly, those who, for whatever reason, feel that "it is not my business" will more likely fail to mediate when exposed to the same scenarios than those who do feel "it is my business". Also, according to a cost-reward model of helping behavior (Piliavin et al., 1981), the lower the sense of responsibility, the lower the psychological costs for not helping, and the lower the probability for helping (i.e., mediating responses).

For reporting responses, however, both perceived severity and sense of personal responsibility appear to play a role in distinguishing those respondents more willing to report to the police when exposed to the same scenarios of IPVAW. Interestingly, we found an interaction effect between perceived severity and sense of personal responsibility, which indicated that the effect of sense of personal responsibility on willingness to report to the police, only takes place for the condition of high perceived severity. That is, we observed differences in reporting responses as a function of sense of personal responsibility, only for those who tend to perceived the same scenarios of IPVAW as more severe (high perceived severity group). For the same hypothetical scenarios of IPVAW, only those who tend to perceive them as more severe, and feel more personally responsible will be more likely to report to the police incidents of IPVAW. These results are in accordance to a decision model of bystander intervention (Latané \& Darley, 1970; Piliavin et al., 1981) in which to reach a certain level of perceived severity is a precondition for the next step in the sequence (i.e. sense of personal responsibility) to operate. Without reaching a certain level of perceived severity the probability to report to the police would be lower. Also, in accordance to a cost-reward analysis of helping (Piliavin et al., 1981), results suggest that for more demanding and costly responses is when perceived severity and personal responsibility would matter the most. As we have seen before, reporting to the police is not the preferred response to incidents of IPVAW. For bystanders, reporting to the police is probably the most costly response to incidents of IPVAW. It may involve potential reprisals from offenders, fear of negative consequences for the women, time consuming involvement or unwanted relationship with the law enforcement system, or even negative reactions from the victims (Apsler, Cummins, \& Carl, 2003; Klein et al., 1997). According to Piliavin et al's. (1981) model of helping behavior, for a bystander to intervene, the psychological costs of not intervening need to be higher than the perceived costs of intervening. High levels of perceived severity and sense of personal responsibility would increase the perceived psychological costs for not intervening, making more likely reporting responses. Finally, our results also suggest that those respondents willing to report to the police not only perceived the same scenarios of IPVAW as more severe, but also favor a norm of social responsibility (e.g. report women in danger), against a social norm concerning "private matters" (e.g. mind your own business) (Darley \& Latané, 1970). This norm, according to Levine (1999), not only guides the interpretation of the event but also the decision about the legitimacy of the intervention.

As for implications for public education and advocacy programs, our results point to the importance of increasing the levels of perceived severity of "all" forms of IPVAW, as well as the sense of personal responsibility to act in "all" cases of IPVAW. To increase feelings of social and personal responsibility towards IPVAW, public education efforts need to promote attitudes that reinforce the helping role of the social circle that surrounds the victim (Gracia, 2004). As Klein et al. (1997) suggested, "we need to educate people to recognize that they have a role in helping battered women and to teach them that their behavior matters, and showed them how to get involved" (p. 90). Community-based policies and interventions need also to address potential conflicts between individual norms of responsibility towards IPVAW and community and social norms about the "private 
matter" that domestic violence still represents (e. g. "mind your own business").

Finally, the study presents some potential limitations. First, the inclusion of other relevant correlates of public responses to cases of IPVAW would help to further understand the processes involved in decision making leading to different types of responses to incidents of IPVAW. The inclusion of other possible predictors of public responses to IPVAW such as the influence of emotional factors, attitudes towards family privacy, victim-blaming attitudes, trust in the authorities' effectiveness, perception of the support available to victims, or contextual effects such as neighborhood social disorder would also help to better understand public responses to incidents of IPVAW (Christy \& Voigt, 1994; Gracia \& Herrero, 2007; Gracia, Herrero, Lila, \& Fuente, 2009; Hadeed \& El-Bassel, 2006; James, Johnson, \& Raghavan, 2004; Levine, 1999; Raghavan, Mennerich, Sexton, \& James, 2006; Weiner, 1980). Another potential limitation is that we used hypothetical scenarios as a stimulus rather than actual situations, and it is possible that public responses might differ from what they actually would do in a real situation (Fritzsche, Finkelstein, \& Penner, 2000; Robinson \& Chandek, 2000).

In conclusion, public concern and awareness of the pervasiveness of domestic violence against women (DVAW) has significantly increased over the last decades. But this growing public concern and awareness needs to translate into a greater personal and collective sense of responsibility to end IPVAW (Klein et al., 1997). Public education campaigns aiming to promote the idea of social responsibility in issues of domestic violence would be better informed through research examining some of the issues explored in this study.

\section{References}

American Medical Association (1994). Diagnostic and treatment guidelines on domestic violence. Chicago, IL: Author.

American Psychological Association Presidential Task Force on Violence and the Family. (1996). Report of the American Psychological Association Task Force on Violence and the Family. Washington, DC: Author.

Apsler, R., Cummins, M. R., \& Carl, S. (2003). Perceptions of the police by female victims of domestic partner violence. Violence Against Women, 9, 1318-1335.

Bachman, R., \& Saltzman, L. E. (1995). Violence against women: Estimates from the redesigned survey. NCJ-154348 Special Report. Washington, DC: U.S. Department of Justice, Bureau of Justice Statistics.

Batson, C. D. (1998). Altruism and prosocial behavior. In D. T. Gilbert, S. Fiske \& G. Lindzey (Eds.), The handbook of social psychology (Vol II, pp. 282-316). New York: McGraw-Hill.

Bennet, L., \& Williams, O. J. (1999). Men who batter. In R. L. Hampton (Ed.), Family violence: Prevention and treatment (2nd Edition) (pp. 227-259). Thousand Oaks, CA: Sage.
Biden, J. R. Jr. (1993). Violence against women: The congressional response. American Psychologist, 48, 1059-1061.

Browne, A. (1993). Violence against women by male partners. American Psychologist, 48, 1077-1085.

Centro de Investigaciones Sociológicas. (2004). Barómetro de Marzo. Estudio $n^{\circ} 2.558$ [Barometer of March. Study $n^{\circ} 2.558$ ]. Madrid, Spain: Author.

Christy, C. A., \& Voigt, H. (1994). Bystander responses to public episodes of child abuse. Journal of Applied Social Psychology, 24, 824-847.

Council of Europe (2002). Recommendation Rec(2002)5 of the Committee of Ministers to member States on the protection of women against violence adopted on 30 April 2002 and Explanatory Memorandum. Strasbourg, France: Council of Europe.

Darley, J. M. \& Latané, B. (1970). Norms and normative behavior: Field studies of social interdependence. In J. Macauley \& L. Berkowitz (Eds.), Altruism and helping behavior (pp. 83-101). New York: Academic Press.

Eagly, A. H., \& Crowley, M. (1986). Gender and helping behavior: A meta-analytic review of the social psychological literature. Psychological Bulletin, 100, 283-308.

European Commission (1999). Europeans and their views on domestic violence against women. Eurobarometer 51.(0). Brussels, Belgium: Author.

Faul, F., Erdfelder, E., Lang, A.-G., \& Buchner, A. (2007). G*Power 3: A flexible statistical power analysis program for the social, behavioral, and biomedical sciences. Behavior Research Methods, 39, 175-191.

Fritzsche, B. A., Finkelstein, M. A., \& Penner, L. A. (2000). To help or not to help: Capturing individuals' decision policies. Social Behavior and Personality, 28, 561-578.

García, J. F., Pascual, J., Frías, M. D., Van Krunckelsven, D., \& Murgui, S. (2008). Design and power analysis: $n$ and confidence intervals of means. Psicothema, 20, 933-938.

García, S. M., Weaver, K., Moskowitz, G. B., \& Darley, J. M. (2002). Crowded minds: The implicit bystander effect. Journal of Personality and Social Psychology, 83, 843-853.

Gracia, E. (2004). Unreported cases of domestic violence against women: Towards an epidemiology of social silence, tolerance, and inhibition. Journal of Epidemiology and Community Health, 58, 536-537.

Gracia, E., García, F. \& Lila, M. (2008). Police involvement in cases of intimate partner violence against women: The influence of perceived severity and personal responsibility. Violence Against Women, 14, 697-714.

Gracia, E., \& Herrero, J. (2006a). Acceptability of domestic violence against women in the European Union: A multilevel analysis. Journal of Epidemiology and Community Health, 60, 123-129.

Gracia, E., \& Herrero, J. (2006b). Public attitudes toward reporting partner violence against women and reporting behavior. Journal of Marriage and Family, 68, 759-768.

Gracia, E., \& Herrero, J. (2007). Perceived neighborhood social disorder and attitudes toward reporting domestic violence against women. Journal of Interpersonal Violence, 22, 737-752. 
Gracia, E., Herrero, J., Lila, M., \& Fuente, A. (2009). Perceived neighborhood social disorder and attitudes toward domestic violence against women among Latin-American immigrants. The European Journal of Psychology Applied to Legal Context, 1, 25-43.

Hadeed, L. F., \& El-Bassel, N. (2006). Social support among AfroTrinidadian women experiencing intimate partner violence. Violence Against Women, 12, 740-760.

Instituto de la Mujer (2003). La violencia contra las mujeres. Resultado de la Macroencuesta de 2002. Madrid: Instituto de la Mujer (http: //www.migualdad.es/mujer/).

James, S. E., Johnson, J., \& Raghavan, C. (2004). "I couldn't go anywhere". Contextualizing violence and drug abuse: A social network study. Violence Against Women, 10, 991-1014.

Jenkins, P. (1996). Threads that link community and family violence: Issues for prevention. In R. L. Hampton, P. Jenkins \& T. P. Gullotta (Eds.), Preventing violence in America (pp. 33-52). London: Sage.

Johnson, M. P., \& Ferraro, K. J. (2000). Research on domestic violence in the 1990s: Making distinctions. Journal of Marriage and the Family, 62, 283 - 294.

Kaufman-Kantor, G., \& Straus, M. A. (1990). Response of victims and the police to assaults on wives. In M. A. Straus \& R. J. Gelles (Eds.), Physical violence in American families: Risk factors and adaptation to violence in 8,145 families (pp. 473487). New Brunswick, NJ: Transaction Publishers.

Klein E., Campbell, J., Soler, E., \& Ghez, M. (1997). Ending domestic violence: Changing public perceptions/halting the epidemic. Thousand Oaks, CA: Sage.

Kury, H., Obergfell-Fuchs, J., \& Woessner, G. (2003). The extent of family violence in Europe. Violence Against Women, 10, 749-769.

Latané, B., \& Darley, J. M. (1970). The unresponsive bystander: Why doesn't he help? New York: Appleton-Century-Crofts.

Latané, B., \& Nida, S. (1981). Ten years of research on group size and helping. Psychological Bulletin, 89, 308-324.

Levine, M. (1999). Rethinking bystander nonintervention: Social categorization and the evidence of witnesses at the James Bulger murder trial. Human Relations, 52, 1133-1155.

Loseke, D. R. (1989). "Violence" is "violence"...or is it? The social construction of "wife abuse" and public policy. In J. Best (Ed.), Images of issues: Typifying contemporary social problems (pp. 191-206). New York: de Gruyter.

Loseke, D. R., \& Gelles, R. J. (1993). Conclusion: Social problems, social policy, and controversies on family violence. In R. J. Gelles \& D. R. Loseke (Eds.), Current controversies on family violence (pp. 357-366). Newbury Park, CA: Sage.

Mahlstedt, D., \& Keeny, L. (1993). Female survivors of dating violence and their social networks. Feminism and Psychology, 3, 319-333.

Muehlenhard, C. L., \& Kimes, L. A. (1999). The social construction of violence: The case of sexual and domestic violence. Personality and Social Psychology Review, 3, 234-245.

Nadine, C., Wathen, M. A., Harriet, L., \& MacMillan, M. D. (2003). Interventions for violence against women: Scientific review. Journal of the American Medical Association, 289, 589-600.
Piliavin, J. A., Dovidio, J. F., Gaertner S. L., \& Clark, R. D., III. (1981). Emergency intervention. New York: Academic Press. Raghavan, C, Mennerich, A., Sexton, E., \& James, S. E. (2006). Community violence and its direct, indirect, and mediating effects on intimate partner violence. Violence Against Women, 12, 1132-1149.

Rhodes, N. R., \& McKenzie, E. B. (1998). Why do battered women stay? Three decades of research. Aggression and Violent Behavior, 3, 391-406.

Robinson, A. L., \& Chandek, M. S. (2000). The domestic violence arrest decision: Examining demographic, attitudinal, and situational variables. Crime \& Delinquency, 46, 18-37.

Schuller, R. A., \& Stewart, A. (2000). Police responses to sexual assault complaints: The role of perpetrator/complainant intoxication. Law and Human Behavior, 24, 535-551.

Shotland, R. L., \& Straw, M. K. (1976). Bystander response to an assault: when a man attacks a woman. Journal of Personality and Social Psychology, 34, 990-999.

Sipsma, E., Carrobles, J. A., Cerrato, I, \& Everaerd, W. (2000). Sexual aggression against women by men acquaintances: Attitudes and experiences among Spanish university students. The Spanish Journal of Psychology, 3, 14-27.

Sorenson, S. B., \& Taylor, C. A. (2005). Female aggression toward male intimate partners: An examination of social norms in a community-based sample. Psychology of Women Quarterly, $29,78-96$.

Staub, E. (2003). Social and prosocial behavior: Personal and situational influences and their interactions. In E. Staub (Ed.), The psychology of good and evil (pp. 103-144). Cambridge: Cambridge University Press.

Straus M. A., \& Gelles, R. J. (1986). Societal change and change in family violence from 1974 to 1985 as revealed by two national surveys. Journal of Marriage and the Family, 48, 465-479.

Walker. L. E. (1999). Psychology and domestic violence around the world. American Psychologist, 54, 21-29.

Watson, D. L., \& Tharp, R. G. (1993). Self-directed behavior: Self modification for personal adjustment (3rd edition). Monterey, CA: Brooks Cole.

Weiner, B. (1980). A cognitive (attribution)-emotion-action model of motivated behavior: an analysis of judgments of help giving. Journal of Personality and Social Psychology, 39, 186-200.

West, A., \& Wandrei, M. L. (2002). Intimate partner violence: A model for predicting interventions by informal helpers. Journal of Interpersonal Violence, 17, 972-986.

Worden, A. P., \& Carlson, B. E. (2005). Attitudes and beliefs about domestic violence: Results of a public opinion survey. II. Beliefs about causes. Journal of Interpersonal Violence, 20, 12191243.

World Health Organization (2002). World report on violence and health. Geneva: World Health Organization.

Received May 23, 2008 Revision received November 5, 2008 Accepted November 17, 2008 